\title{
PERCEPÇÕES DE ALUNOS DO ENSINO FUNDAMENTAL SOBRE O BIOMA PAMPA, NO OESTE DO RIO GRANDE DO SUL, BRASIL
}

\author{
Luis Roberval Bortoluzzi Castro' \\ Andriélli Vilanova de Carvalho2 \\ Edward Frederico Castro Pessano ${ }^{3}$
}

\section{RESUMO}

A percepção ambiental é uma ferramenta capaz de diagnosticar a relação do ser humano com o meio ambiente, possibilitando estabelecer estratégias e ações na busca da preservação ambiental. Nesse sentido, o Pampa tem destaque devido a sua importância biológica que sustenta boa parte da economia do bioma. Porém, nas últimas décadas, o Pampa vem apresentando consideráveis problemas ambientais. Desse modo, surge a necessidade de investigar as percepções de alunos do ensino básico a respeito dos seus conhecimentos sobre temas relacionados ao Pampa. Participaram desta pesquisa 94 alunos do $9^{\circ}$ ano do ensino fundamental, de três escolas públicas, do município de Uruguaiana, RS, e a coleta de dados foi realizada mediante a aplicação de um questionário constituído por questões abertas e fechadas, sendo as respostas analisadas qualiquantitativamente. Os resultados permitem inferir que a maioria dos alunos possuem percepções inadequadas e fragmentadas sobre o bioma Pampa. Neste contexto, a pesquisa fornece informações para a comunidade acadêmica, a fim de promover intervenções para a melhoria das práticas pedagógicas, bem como na promoção de atividades contextualizadas que auxiliem na expansão do conhecimento ambiental regional.

Palavras-chave: Bioma Pampa. Contextualização. Ensino de Ciências.

\footnotetext{
1 Doutorando do PPG Educação em Ciências Química da Vida e Saúde na Fundação Universidade Federal do Pampa, Mestre em Educação em Ciências e especialista em Educação Ambiental pela Universidade Federal de Santa Maria. Atualmente pesquisador colaborador junto ao Laboratório de Biologia e Diversidade Animal da Universidade Federal do Pampa. E-mail: Ibortoluzzi@gmail.com

2 Doutoranda do PPG Educação em Ciências Química da Vida e Saúde na Fundação Universidade Federal do Pampa. Mestra em Educação em Ciências pela Universidade Federal de Santa Maria - RS. Docente da Educação Básica no Município de Uruguaiana. Email: carvalho.andrielli@gmail.com

3 Doutor em Educação em Ciências pela UFSM. Atualmente é Professor na Fundação Universidade Federal do Pampa. E-mail: edward.pessano@unipampa.edu.br
} 


\title{
PERCEPTIONS OF STUDENTS OF FUNDAMENTAL EDUCATION ON PAMPA BIOME, WEST OF RIO GRANDE DO SUL, BRAZIL
}

\begin{abstract}
Environmental perception is a tool capable of diagnosing the human being's relationship with the environment, making it possible to establish strategies and actions in the pursuit of environmental preservation. In this sense, the Pampa is highlighted due to its biological importance that sustains a good part of the biome economy. However, in the last decades the Pampa has presented considerable environmental problems. In this sense, the need arises to investigate the perceptions of students of basic education regarding their knowledge on subjects related to Pampa. A total of 94 students from the 9th year of elementary school in three public schools in the city of Uruguaiana participated in this study. Data collection was done through the application of a questionnaire consisting of open and closed questions, the answers were qualitatively and quantitatively analyzed. The results allow to inferring that the majority of students have inadequate and fragmented perceptions about the Pampa biome. In this context, the research provides information for the academic community, in order to promote interventions for the improvement of pedagogical practices, as well as in the promotion of contextualized activities that can help in the expansion of regional environmental knowledge.
\end{abstract}

Keywords: Pampa Biome. Contextualization. Science teaching.

\section{PERCEPCIONES DE ESTUDIANTES DE LA ENSEÑANZA FUNDAMENTAL SOBRE EL BIOMA PAMPA, EN EL OESTE DEL RIO GRANDE DEL SUR, BRASIL.}

\section{RESUMEN}

La percepción ambiental es una herramienta capaz de diagnosticar la relación del ser humano con el medio ambiente, posibilita establecer estrategias y acciones en la búsqueda de la preservación ambiental. En ese sentido, la Pampa destaca por su importancia biológica que sostiene buena parte de la economía del bioma. Sin embargo, en las últimas décadas el Pampa viene presentando considerables problemas ambientales. En este sentido, surge la necesidad de investigar las percepciones de alumnos de la enseñanza básica acerca de sus conocimientos sobre temas relacionados con la Pampa. En el presente trabajo se analizaron los resultados obtenidos en el análisis de los resultados obtenidos en el estudio de los resultados obtenidos en el estudio. Los resultados permiten inferir que la mayoría de los alumnos poseen percepciones inadecuadas y fragmentadas sobre el bioma Pampa. En este contexto, la investigación proporciona informaciones para la comunidad académica, a fin de promover intervenciones para la mejora de las prácticas pedagógicas, así como en la promoción de actividades contextualizadas que puedan auxiliar en la expansión del conocimiento ambiental regional.

Palabras clave: Bioma Pampa. Contextualización. Enseñanza de Ciencias. 


\section{INTRODUÇÃO}

As últimas décadas foram marcadas pelas grandes inovações, principalmente as de ordem tecnológica, e essas rápidas mudanças têm ocasionado variados conflitos de ideias que atingem a sociedade e incitam a alteração de paradigmas (DÁVILA, FOLMER e PUNTEL, 2017).

Atualmente, vivemos cercados por várias crises, dentre elas, está a ambiental, que nos remete a inúmeros questionamentos referentes ao modo como os seres humanos se relacionam com os elementos que os cercam (SANTOS et al., 2013).

Ao observar a crise ambiental no Brasil, é possível perceber que a deterioração dos ecossistemas está relacionada com os valores culturais, sociais, econômicos da sociedade.

Para Bigliardi e Cruz (2008), o modelo de vida da sociedade é reflexo da lógica capitalista, em que o crescimento econômico está acima de tudo e a exploração dos recursos naturais se torna algo necessário, gerando problemas crônicos na sociedade, como a exclusão social e o crescimento populacional desordenado. Com isso, os ecossistemas são degradados e a biodiversidade vai sendo exterminada antes mesmo da ciência conhecer.

Estudos apontam que a intervenção humana descontrolada está diretamente associada à degradação ambiental, visto que modificam os ecossistemas, afetam a biodiversidade e está relacionada à perda de qualidade de vida da população.

Nesse caminho, o conhecimento dos ecossistemas locais se torna cada vez mais prioritário para a conservação do ambiente natural. Dentre os ecossistemas brasileiros, destaca-se o bioma Pampa, denominado cientificamente como um conjunto de ecossistemas que comporta uma significativa biodiversidade de importância mundial.

O Pampa é o único bioma brasileiro restrito a um estado, representando cerca de $2 \%$ do território nacional, é considerado a marca do território gaúcho pelo desenvolvimento econômico alicerçado nos diversos fatores biológicos que sustentam a qualidade cultural, ambiental e econômica do bioma. 
O Pampa é considerado internacionalmente uma das áreas de maior prioridade para a conservação devido a sua biodiversidade ainda desconhecida pela ciência. Porém, está sofrendo uma considerável crise de desvalorização ambiental devido à descaracterização das suas paisagens, sendo apontado como um bioma negligenciado (OVERBECK et al., 2009).

Diante dessa omissão social, percebe-se a importância econômica e biológica do Pampa, assim como a distância entres esses dois fatores, dado que a literatura aponta anualmente a perda de áreas e da diversidade do bioma. Chomenko (2007) indica que uma das maneiras mais eficientes de aproximar esses dois fatores de forma sustentável, estaria relacionado com o conhecimento da população a respeito do ambiente em que vivem e isso só seria possível por meio da educação.

Todo esse descuido com o Pampa surge da ausência de conhecimentos, em que os fatores biológicos não são relacionados com os fatores econômicos. Nesse caminho, Suertegaray e Silva (2009) reforçam a necessidade dos saberes locais para a valorização de uma região.

Esse conhecimento está assegurado nas diretrizes educacionais do país, em que, nos objetivos dos Parâmetros Curriculares Nacionais (PCN's), o conhecimento da diversidade de vida no planeta é importante e prioriza os saberes voltados aos ecossistemas brasileiros, além do conhecimento local, no qual, cada estudante vive (BRASIL, 1998b).

Pessano et al. (2015) reforçam que a exploração dos conhecimentos locais, no ensino básico, é importante para a compreensão de temas ambientais, pois possibilitam uma maior identificação com seu meio, propiciando a habilidade de reconhecer a sua e das demais regiões do país e valorizá-las, posicionando-se e buscando resoluções frente a possíveis problemas.

Compreendendo o Pampa como um dos seis biomas oficiais do Brasil, com uma biodiversidade peculiar e de importância econômica inquestionável, negligenciado governamentalmente e também considerado um descaso no processo educativo do ensino básico, este trabalho teve por objetivo diagnosticar a percepção de alunos do ensino fundamental de três 
escolas públicas, do oeste do estado do Rio Grande do Sul, sobre temáticas relacionadas com o Bioma Pampa, presentes nos conteúdos educacionais e, assim, verificar o quanto essa etapa de ensino contribui para com a formação dos alunos.

\section{O BIOMA PAMPA}

O bioma Pampa apresenta uma área de aproximadamente $750.000 \mathrm{~km}^{2}$ (MAZURANA et al., 2016) e é compartilhado por Argentina, Brasil e Uruguai. No território brasileiro, abrange, exclusivamente, o estado do Rio Grande do Sul, ocupando a metade sul e a região sudoeste do estado, equivalendo a $177.767 \mathrm{~km}^{2}$ (BRASIL, 2011) ou cerca de $63 \%$ do território gaúcho (BRASIL, 2004; CHOMENKO, 2007; BOLDRINI et al., 2010).

As áreas de campo do Pampa são consideradas entre as mais importantes do planeta, devido a sua variedade de paisagens naturais, que apresentam desde serras até planícies, de morros rupestres a coxilhas, dando significância a um patrimônio cultural totalmente associado à biodiversidade (BENKE, 2006).

Embora seja um dos menores biomas brasileiros em termos de território, - Pampa apresenta particularidades devido a sua flora e fauna próprias, que atribuem consideráveis estimativas a sua biodiversidade ainda não conhecida completamente pela ciência (CHOMENKO, 2006).

Trata-se de um patrimônio natural, genético e cultural de importância internacional e que, além disso, comporta a maior parte do aquífero Guarani, contudo, a degradação ambiental vem sendo sinalizada pelos cientistas (CHOMENKO, 2006; BENKE, 2006; 2007).

Muitos são os estudos que indicam consideráveis perdas e alterações do Pampa, isso se deve, principalmente, pela ampliação de processos agropecuários de larga escala, aliada ao crescimento urbano. Pillar (2006) e Brack (2007) relatam que a progressiva introdução e expansão das monoculturas e das pastagens com espécies exóticas têm levado a uma rápida degradação e descaracterização das paisagens naturais do Pampa. 
Segundo König et al., (2014), o Pampa possui uma diversidade de espécies vegetais que compõe um mosaico genético riquíssimo, porém pouco reconhecido no Brasil. A valorização do Pampa é fundamental para a preservação das espécies, não só no aspecto ambiental, mas econômico e social, visto que, o uso do bioma está associado à pecuária e ao campo nativo, o qual exerce um importante papel no controle da erosão (SANTOS, 2015).

Ainda, as riquezas culturais e biológicas do Pampa possuem um carácter internacional, por isso é digno de atenção, quanto a estudos que visem sua preservação e discutam estratégias para sustentabilidade (DEBLE, DEBLE e LEÃO, 2012). Apesar de ser um bioma importante, devido a sua biodiversidade que reflete diretamente nos setores econômicos, ainda é um ecossistema desconhecido (PILLAR, 2006).

\section{O BIOMA PAMPA E A EDUCAÇÃO BÁSICA}

É possível dizer que o Pampa é um bioma novo, conhecido oficialmente pelo Instituto Brasileiro de Geografia e Estatística em 2004 e pelo Ministério do Meio Ambiente em 2007 (BRASIL, 2004; BORTOLUZZI e SOUZA, 2007). Entretanto, antes desse reconhecimento, o espaço natural já existia e, consequentemente, a exploração também. Atualmente, os avanços da ciência ressaltam a importância desse conjunto de ecossistemas, em que, muitos pesquisadores consideram que o Pampa é um dos biomas mais negligenciados do país (BOLDRINI et al., 2010; OVERBECK et al., 2009).

Correa (2008), ao investigar a percepção de alunos do ensino básico no estado do Rio Grande do Sul, identificou que o tema era pouco explorado e concluiu que muitos dos problemas ambientais relacionados ao Pampa estavam iniciando pelo setor educacional, que não estava desenvolvendo o tema de maneira significativa e, ainda, destacou isso como um descaso com o Pampa.

Tendo em vista os grandes desafios do setor educacional, Camargo (2003) ressalta como sendo um deles, a falta de material didático adequado 
e o distanciamento dos alunos do ambiente natural, tornando-se a causa do desconhecimento a respeito dos temas ambientais.

No entanto, os PCN's, para todas as etapas do ensino básico, destacam que os conteúdos devem capacitar o estudante para uma visão de mundo, onde o ser humano seja agente transformador.

E, desse modo, o estudo da percepção ambiental fornece dados para estabelecer ações de preservação em conjunto com o tema transversal meio ambiente, no qual a escola, enquanto formadora de cidadãos, tem o papel de orientar os estudantes para refletirem a respeito das suas atividades no meio em que vivem (BRASIL, 1998a).

Dessa maneira, a escola se torna um espaço privilegiado para o desenvolvimento da educação ambiental, que é uma ferramenta para o diagnóstico e a análise da percepção dos estudantes em relação aos temas ambientais, possibilitando a participação dos cidadãos na resolução de situações problemas e nas práticas preventivas quanto à conservação ambiental, de acordo com as necessidades de cada local (PALMA, 2005; POLLI e SIGNORINI, 2012).

No momento atual, a educação ambiental se estabelece como propriedade para superar a visão meramente ecológica, ampliando seu horizonte com discussões políticas, sociais, econômicas, culturais e ambientais (SPIRONELLO et al., 2012). Caracterizada pelo despertar do indivíduo às questões relacionadas à preservação e conservação ambiental, a educação ambiental auxilia na tomada de decisões (SOUZA, 2014).

Entretanto, quando a sociedade chega ao ponto de negligenciar 0 ambiente responsável pelo desenvolvimento econômico local e quando toda ação ambientalmente impactante se torna comum, surge um alerta, denominado por Auller e Delizoicov (2001) de ausência de conhecimento científico, que dificulta o desenvolvimento das habilidades necessárias para os estudantes. Desse modo, os autores defendem que o conhecimento científico deveria ser realmente trabalhado no ensino básico (AULLER e DELIZOICOV, 2001). 
Esse conhecimento científico vai além do cidadão conseguir interpretar uma bula médica, mas também, desenvolver capacidades, que, no caso dos ecossistemas, a capacidade do cidadão de refletir sobre problemas que ocorrem em sociedade, como a forte ação antrópica exercida no Pampa a partir da agricultura, silvicultura e monocultura (BENCKE, 2006; CHOMENKO, 2007; LANNA, 2007; MADEIRA, 2007), ou a introdução direta ou indireta de espécies exóticas (CHOMENKO, 2006) e até mesmo da biopirataria (BRACK, 2007), quando somados, esses problemas caracterizam o Pampa como um dos ecossistemas mais degradados do país, com redução significativa dos seus habitats (OVERBECK et al., 2009).

Tudo isso exposto, quando não trabalhado no ensino básico de maneira problematizadora e contextualizadora como preconizam os PCN's, além de proporcionar o distanciamento dos estudantes de as suas raízes, podem afetar a construção de visão crítica, nesse caso, relacionado ao meio ambiente, visto que não se preserva o que não se conhece.

\section{PERCURSO METODOLÓGICO}

O presente estudo foi realizado com 94 alunos do $9^{\circ}$ ano do Ensino Fundamental de três escolas públicas, localizadas em diferentes contextos no município de Uruguaiana, RS (figura 1). 
FIGURA 1 - Localização do Município de Uruguaiana, RS, Brasil

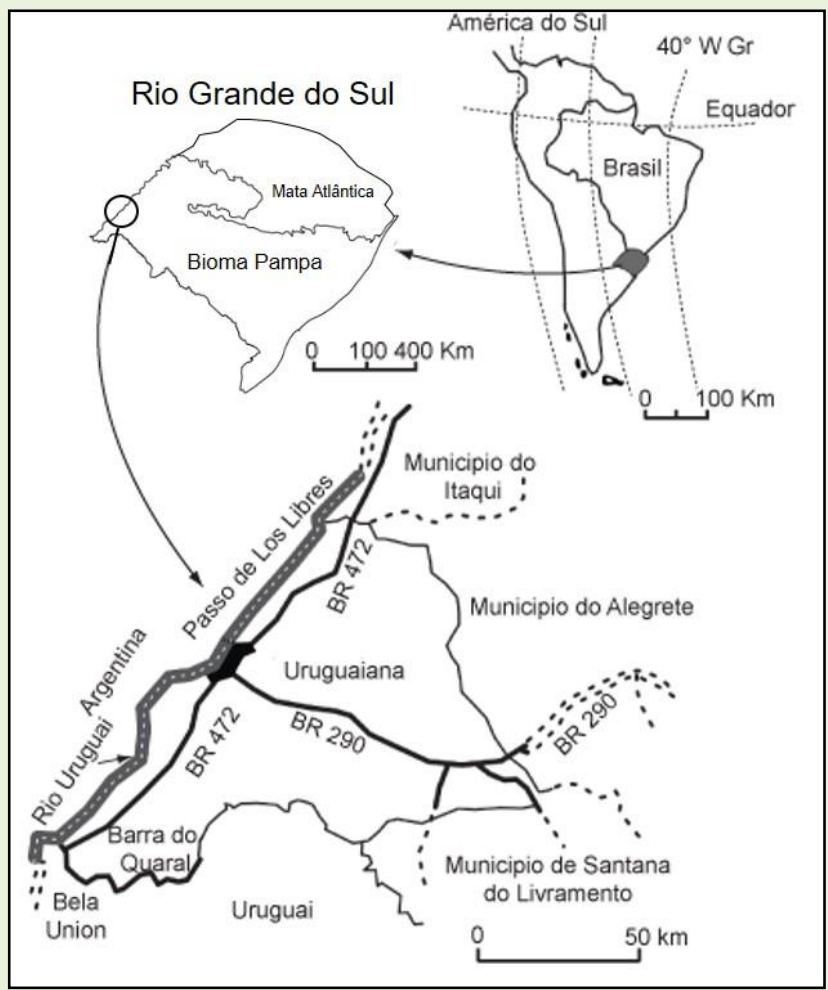

Fonte: Bortoluzzi et al., (2007).

Foram convidadas a participar do presente estudo, todas as escolas da rede pública com ensino básico completo, contudo, manifestaram interesse três unidades escolares: uma situada na periferia, outra na área central e a última na zona rural do município.

Logo após ao aceite das escolas, o projeto foi registrado com CAAE: 60374216.3.0000.5323, aprovado pelo Comitê de Ética em Pesquisa da Universidade pelo parecer $n^{\circ} 1.840 .202$ e pelo parecer de aprovação da coleta de dados $n^{\circ} 2.063 .911$.

Nesta trajetória, o tamanho da amostra foi definido conforme o interesse das instituições de ensino e de acordo com a autorização dos responsáveis pelos alunos, totalizando 94 participantes identificados de A1 a A94, sendo 30 alunos representantes da escola 1 (E1), 31 alunos da escola 2 (E2) e 33 alunos participantes da escola 3 (E3).

Os dados foram coletados por meio da aplicação de formulário semiestruturado constituído por duas seções, a primeira foi referente ao perfil 
(gênero) e a segunda dividida em dois blocos compostos de seis questões principais fechadas e desdobradas em sub questões abertas (Quadro 01).

QUADRO 1 - Questões do formulário aplicado aos participantes da pesquisa

\section{BLOCO 1:}

1. Você tem conhecimento sobre o tema Bioma? $\square$ sim $\square$ não

a. Se SIM, o que sabe?

2. Você tem conhecimento sobre o tema Bioma Pampa? $\square$ sim $\square$ não

a. Se SIM, o que sabe?

3. Você sabe o que é meio ambiente? $\square$ sim $\square$ não

Para você o que é meio ambiente?

\section{BLOCO 2:}

4. Você tem conhecimento sobre Monocultura? $\square$ sim $\square$ não

a. Se SIM, o que sabe?

5. Você tem conhecimento sobre espécie nativa e exótica? $\square \operatorname{sim} \square$ não

a. Se SIM, o que sabe?

6. Você tem conhecimento sobre Biopirataria? $\square$ sim $\square$ não

a. Se SIM, o que sabe?

$$
\text { Fonte: Dados adaptados de Correa (2008). }
$$

O bloco 1, composto pelas questões 1,2 e 3, buscou verificar as percepções sobre os temas bioma, bioma pampa e meio ambiente, já o bloco 2, composto pelas questões 4, 5 e 6, buscou analisar as percepções frente a problemas ambientais existentes no Pampa e, com isso, correlacionar o aprendizado com situações existentes no cotidiano dos alunos.

Os conteúdos das questões fechadas foram analisados estatisticamente pelo Teste de Kruskal Wallis - KW, com objetivo de diagnosticar se haviam diferenças significativas entre os resultados dos diferentes grupos.

As respostas dissertativas foram organizadas de acordo com a similaridade, frequência de percentuais e categorizadas seguindo a análise de conteúdo de Bardin (2011), na qual, para as questões 1, 2, 4, 5 e 6, elaborou-se uma matriz de categorias para análise das respostas (tabela 1). 
TABELA 1 - Categorias para as repostas das questões (1, 2, 4, 5 e 6)

\begin{tabular}{l|l}
\hline \multicolumn{1}{c|}{ CATEGORIA } & \multicolumn{1}{c}{ DESCRIÇÃO } \\
\hline Abstenção & Quando não responde. \\
\hline Inadequada & $\begin{array}{l}\text { Quando responde sem relação com } \\
\text { o questionado. }\end{array}$ \\
\hline Fragmentada & $\begin{array}{l}\text { Quando cita alguns elementos que } \\
\text { apresentam relação com o tema de } \\
\text { forma ampla, solta, vaga e/ou } \\
\text { quando cita um ou mais elementos e } \\
\text { deixa a resposta confusa. }\end{array}$ \\
\hline Adequada parcialmente & $\begin{array}{l}\text { Quando cita alguns elementos de } \\
\text { acordo com tema de forma } \\
\text { apropriada, porém não os relaciona. }\end{array}$ \\
\hline Adequada & $\begin{array}{l}\text { Quando cita alguns elementos de } \\
\text { acordo com tema de forma } \\
\text { apropriada e os relaciona. }\end{array}$ \\
\hline Esperada & $\begin{array}{l}\text { Quanto a resposta atinge o } \\
\text { esperado nos PCNs, o aluno cita } \\
\text { elementos relacionados ao tema, se } \\
\text { posiciona perante ao que foi } \\
\text { questionado e contextualiza. }\end{array}$ \\
\hline
\end{tabular}

Fonte: Dados da Pesquisa.

As respostas da questão $n^{\circ} 3$ (O que é meio ambiente?) também foram categorizadas seguindo Bardin (2011), (tabela 2), com objetivo de diagnosticar o perfil dos alunos sobre o tema meio ambiente.

TABELA 2 - Categorias para as repostas da questão o que é meio ambiente

\begin{tabular}{|c|c|}
\hline CATEGORIA & DESCRIÇÃO \\
\hline Utilitarista & Percebe a exploração dos recursos \\
\hline Conservador & $\begin{array}{l}\text { Enfatiza a preservação e os cuidados } \\
\text { necessários }\end{array}$ \\
\hline \multicolumn{2}{|l|}{ Utilitarista/Conservador } \\
\hline Teórico & $\begin{array}{l}\text { Percebe o meio ambiente como um } \\
\text { conteúdo/tema }\end{array}$ \\
\hline Estético & $\begin{array}{l}\text { Percebe o meio ambiente citando } \\
\text { elementos individuais da natureza }\end{array}$ \\
\hline \multicolumn{2}{|l|}{ Estético/conservador } \\
\hline Estético/utilitarista & \\
\hline Inadequada & \\
\hline
\end{tabular}

Fonte: Dados da Pesquisa. 


\section{RESULTADOS}

Dos 94 alunos finalistas do ensino fundamental das três escolas participantes, $32 \%$ representaram a E1, 33\% a E2 e 35\% a E3 (figura 2).

FIGURA 2 - Percentual amostral de participantes da pesquisa, por escola.

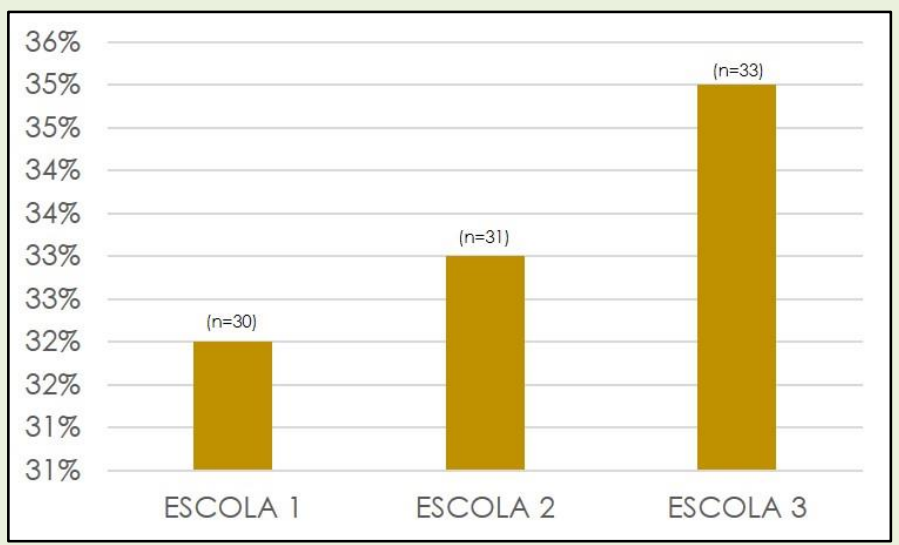

Fonte: Dados da Pesquisa.

O gênero feminino apresentou-se com $53 \%$, seguido de $47 \%$ do gênero masculino. Em relação às unidades amostradas, o gênero feminino apresentou maior proporção na El, com 67\%, para as E2 e E3, o gênero masculino foi mais presente, com 62\% e 55\%, respectivamente (Figura 3).

FIGURA 3 - Perfil de gênero dos participantes da pesquisa, por escola.

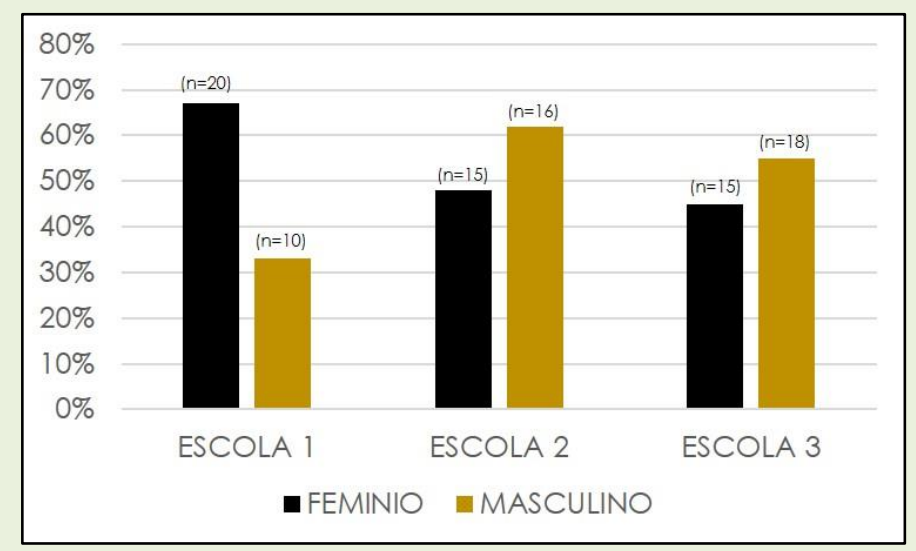

Fonte: Dados da Pesquisa.

Quando avaliados estatisticamente os grupos, pelo Teste de Kruskal Wallis - KW, em relação aos dados relacionados ao diagnóstico, percebe-se 
que existe diferença significativa para as questões 1, 2 e 4 e todas foram relacionadas à E3, na qual, O percentual das respostas de E1 e E2 apresentaram similaridade, já as respostas da E3 não seguiram o mesmo padrão (Tabela 3). Nas demais questões, não foram encontradas diferenças significativas, apresentando uma padronização das informações fornecidas pelos grupos.

TABELA 3 - Percentual e análise estatística das respostas dos alunos das três escolas, em relação às perguntas de 1 a 6 , durante a etapa da investigação

\begin{tabular}{l|c|c|c|c|c|c|c}
\hline & \multicolumn{2}{|c|}{ E1 } & \multicolumn{2}{c|}{ E2 } & \multicolumn{2}{c|}{ E3 } & \multicolumn{1}{|c|}{$\begin{array}{c}\text { Análise } \\
\text { Estatística } \\
\text { KW }\end{array}$} \\
\hline \multicolumn{1}{c|}{ Questões } & Sim & Não & Sim & Não & Sim & Não & Valor de P \\
\hline $\begin{array}{l}\text { 1)Você tem conhecimento sobre } \\
\text { o tema Bioma? }\end{array}$ & $40 \%$ & $60 \%$ & $48 \%$ & $52 \%$ & $\underline{12 \%}$ & $\underline{88 \%}$ & $\mathbf{0 , 0 0 5 6 ^ { * }}$ \\
\hline $\begin{array}{l}\text { 2)Você tem conhecimento sobre } \\
\text { o tema Bioma Pampa? }\end{array}$ & $7 \%$ & $93 \%$ & $26 \%$ & $74 \%$ & $\underline{61 \%}$ & $\underline{39 \%}$ & $\mathbf{0 , 0 0 0 1 ^ { * }}$ \\
\hline $\begin{array}{l}\text { 3)Você sabe o que é meio } \\
\text { ambiente? }\end{array}$ & $97 \%$ & $3 \%$ & $90 \%$ & $10 \%$ & $91 \%$ & $9 \%$ & 0,5833 \\
\hline $\begin{array}{l}\text { 4)Você tem conhecimento sobre } \\
\text { Monocultura? }\end{array}$ & $23 \%$ & $77 \%$ & $35 \%$ & $65 \%$ & $\underline{9 \%}$ & $\underline{91 \%}$ & $\mathbf{0 , 0 4 1 3 ^ { * }}$ \\
\hline $\begin{array}{l}\text { 5)Você tem conhecimento sobre } \\
\text { espécie nativa e exótica? }\end{array}$ & $40 \%$ & $60 \%$ & $29 \%$ & $71 \%$ & $21 \%$ & $79 \%$ & 0,2676 \\
\hline $\begin{array}{l}\text { 6)Você tem conhecimento sobre } \\
\text { biopirataria? }\end{array}$ & $20 \%$ & $80 \%$ & $13 \%$ & $87 \%$ & $21 \%$ & $79 \%$ & 0,6554 \\
\hline
\end{tabular}

* Resultados com nível de significância $=p<0,05$.

Fonte: Dados da Pesquisa.

Em relação ao questionamento "você sabe o que é bioma?", observase que a maioria dos alunos da E3 (88\%), da E1 (60\%) e da E2 (52\%) indicaram desconhecer o tema (Figura 4a), sendo possível observar que as escolas El e E2 mantiveram uma média de $56 \%$ quando indicaram desconhecer o tema, enquanto $88 \%$ da E3 indicaram o mesmo. Embora o percentual das respostas de E3 tenha sido mais significativo, quando comparados com E1 e E2, as informações indicam o desconhecimento do tema, ficando evidente, com a análise das respostas descritivas categorizadas, em sua maioria, como fragmentadas (figura $4 b$ ). 
FIGURA 4 - A) Percentual por escola das respostas da pergunta: Você tem conhecimento sobre o tema Bioma. B) Categorização das respostas descritivas

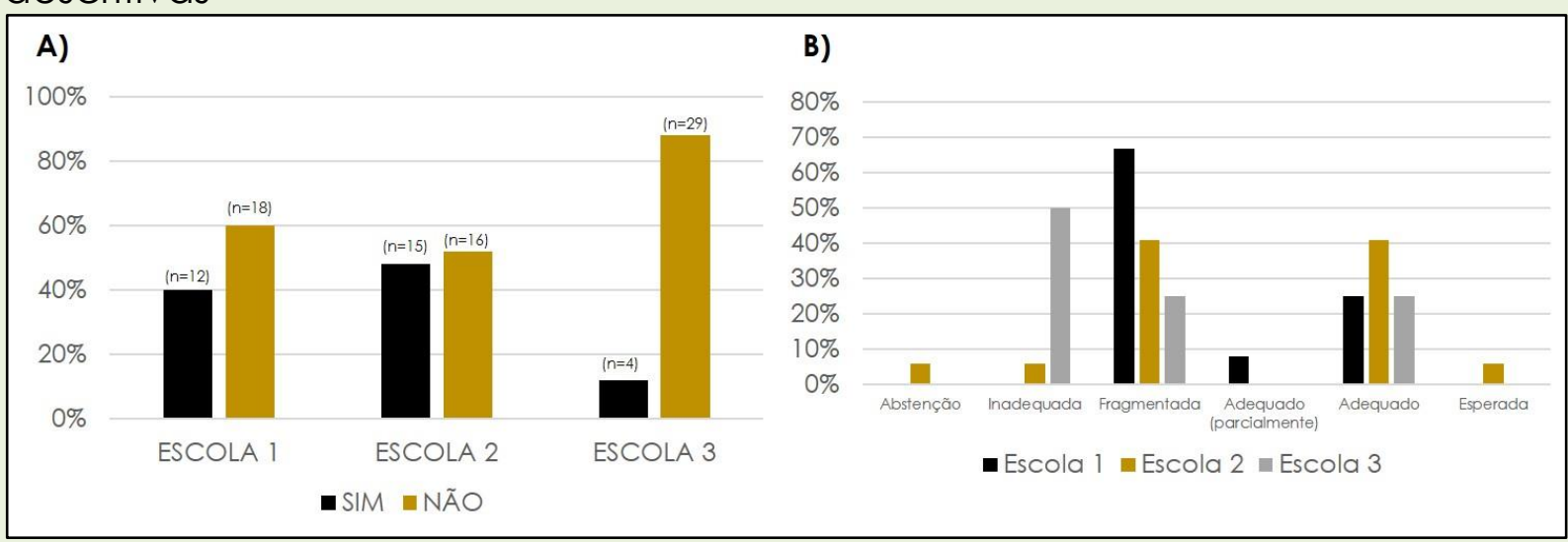

Fonte: Dados da Pesquisa.

A categoria fragmentada foi relacionada às respostas incompletas ou confusas, conforme as afirmações dos alunos:

A11 - Seria algo ligado a "biodiversidade?" algo ligado à natureza e tudo que " $a$ " nela;

A18 - Que é relacionado a animais e plantas e várias coisas "diferente" a natureza, já ouvi falar, mas esqueci.;

A80-bioma é algo a respeito da natureza.

Também ocorreram as informações categorizadas como adequadas conforme segue:

A25 - Bioma de neve, floresta ou algo relacionado com algum lugar.

A39 - um conjunto de vegetações que define uma região.

A92 - Bioma acredito que seja um conjunto de vegetação.

Além das informações categorizadas como inadequadas, expressiva para a E3, conforme as respostas dos alunos:

A 34 - não lembro.

A94 - É uma célula cancerígena; e

No questionamento sobre o bioma Pampa, a maioria dos alunos da El (97\%) e E2 (74\%) informou não saber sobre o tema, e $61 \%$ da E3 
responderam ter conhecimento (Figura 5a), fator esse que, no primeiro momento, gerou significância entre as informações dos grupos, porém, quando foram analisadas as respostas descritivas, observou-se que $100 \%$ dos alunos da E3 não responderam o que seria o bioma Pampa e a análise das demais respostas variaram entre fragmentadas e adequadas (figura 5b).

FIGURA 5 - A) Percentual por escola das respostas da pergunta: Você tem conhecimento sobre o tema Bioma Pampa. B) Categorização das respostas descritivas

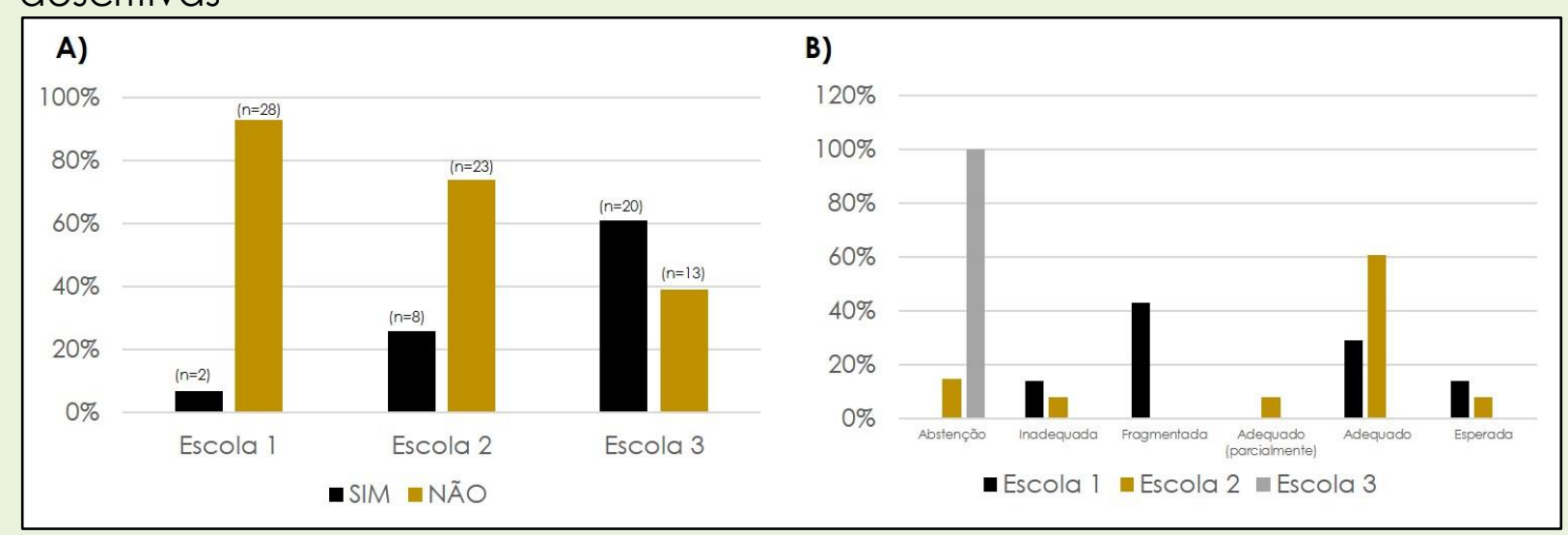

Fonte: Dados da Pesquisa.

As respostas categorizadas como fragmentas dos representantes da El são:

A11 - Algo ligado ao campo;

A15 - Que é um bioma e que é do Pampa.

Já as categorizadas como adequadas dos representantes da E1 e E2:

A2 - "É" as características da vegetação da nossa região;

A26 - Bioma pampa são os campos situados no Rio Grande do

Sul.

A38- São os campos, as gramas do sul do Brasil.

Assim como as repostas esperadas, como as dos alunos:

A12 - É o bioma da metade do "rio grande do sul" e seu espaço geográfico e plano compostos por campos e coxilhas etc.;

A47 - O bioma pampa é uma região pastoril de planícies presentes só no do Rio Grande do Sul. 
A terceira questão não apresentou variação significativa entre as informações fechadas, dado que a grande maioria dos alunos indicou ter conhecimento sobre o tema meio ambiente (Figura 6a). Os alunos, quando questionados a descreverem o que seria meio ambiente, na El destacaram a categoria estético, com 31\%, seguida das categorias teórico e conservador, com $21 \%$ cada, na E2 a categoria conservador foi mais expressiva, com $29 \%$, seguida da categoria estético, com $25 \%$, e na E3 a categoria conservador apresentou $24 \%$, seguida das categorias estético, teórico e inadequado, com $23 \%$ cada (figura 6b).

FIGURA 6 - A) Percentual por escola das respostas da pergunta: Você sabe o que é meio ambiente. B) Categorização das respostas descritivas

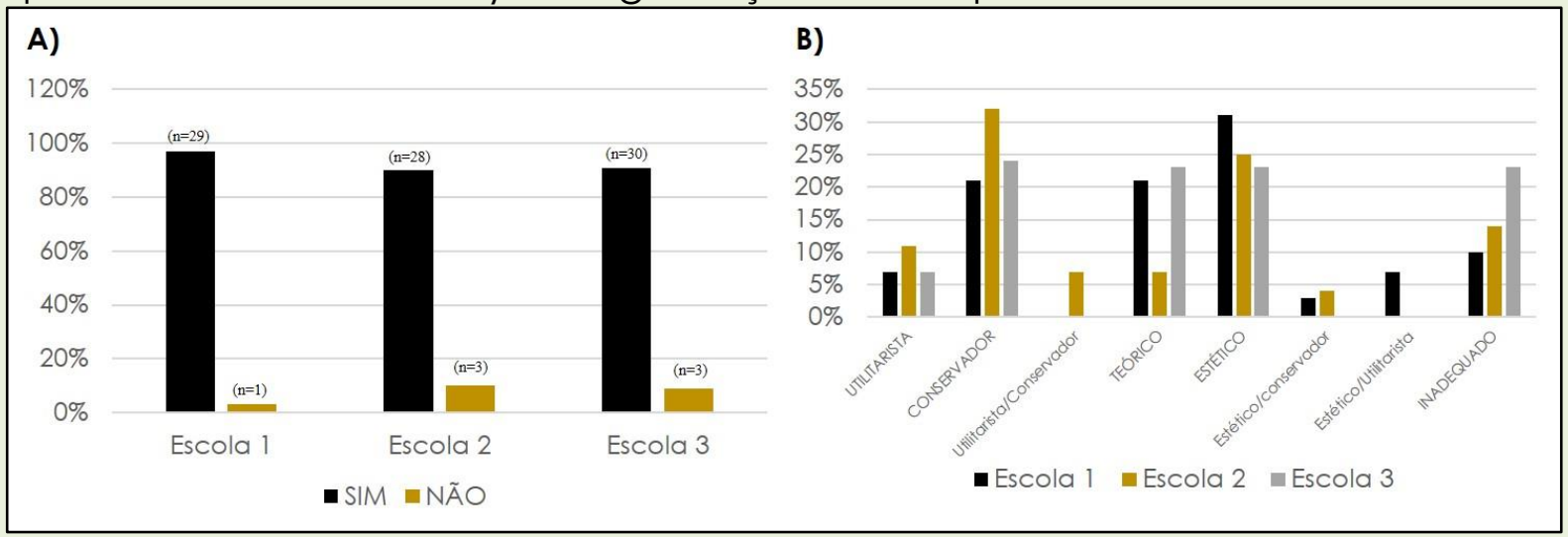

Fonte: Dados da Pesquisa.

Percebe-se que as categorias estético e conservador foram as mais representadas nas três escolas, sendo que a categoria estético representou os alunos que percebem o meio ambiente por meio de elementos isolados, conforme pode-se ver nas informações dos alunos:

A19 - O as florestas, animais que vivem na mata;

A33 - O meio ambiente é o lugar em que vivemos;

A72 - A terra o mato e os rios e animais.

Já a categoria conservador foi relacionada para as respostas que direcionam o meio ambiente com o ato de preservação ou cuidados, como nas respostas dos alunos: 
A20 - Meio ambiente é sobre não jogar lixo no chão é reciclar é cuidar do seu mundo sem poluir.;

A34 - Devemos proteger o meio ambiente;

A87 - Preservar a natureza.

Para a questão relacionada ao tema monocultura, foi possível observar que a maioria dos alunos da E3 (91\%), 77\% da E1 e $67 \%$ da E2 responderam não terem conhecimento sobre o tema (Figura 7a) e as respostas descritivas, quando analisadas, foram categorizadas em inadequadas por $64 \%$ dos alunos da E1 e $33 \%$ da E2 e adequadas para $33 \%$ dos alunos da E3, 18\% da E2 e $14 \%$ da E1 (Figura 7b).

Figura 7 - A) Percentual por escola das respostas da pergunta: Você tem conhecimento sobre monocultura. B) Categorização das respostas descritivas

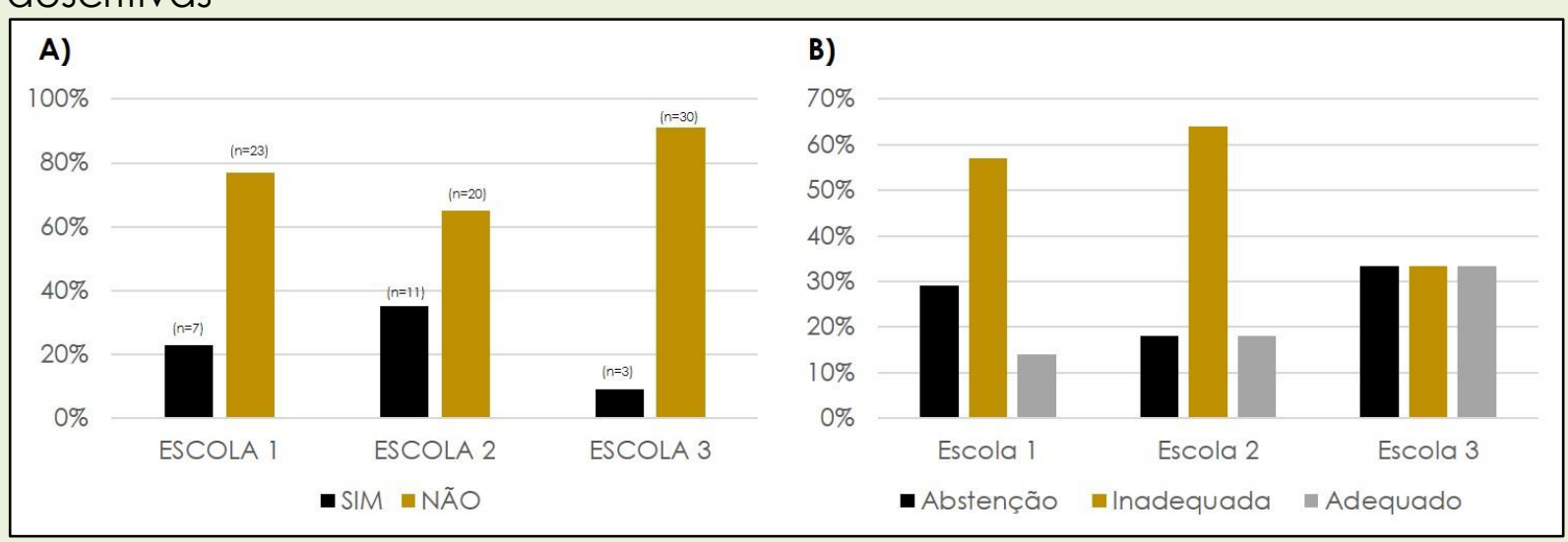

Fonte: Dados da Pesquisa.

Ainda em relação às respostas descritivas que foram categorizadas como inadequadas, foi possível observar que os alunos relacionaram a monocultura com tradição e com arte, como pode ser observado nas respostas:

A21 - Estuda a cultura de um lugar;

A37 - A monocultura é a arte;

A72 - Mono é uma e Cultura é várias. 
Já as respostas adequadas relacionaram a monocultura com o ato de plantar uma espécie em um dado local, como visto nas respostas dos alunos:

A13 - A cultura de cultivar uma coisa só;

A46 - é um tipo de plantio no mesmo lugar;

A71 - é um lugar que se planta uma coisa só;

Em relação à questão sobre as espécies nativas e exóticas, as respostas fechadas não apresentaram significância entre os grupos, $79 \%$ dos alunos de E3, seguido por $71 \%$ de E2 e $60 \%$ de E1 desconheciam o tema (Figura 8a). Com isso, a análise das informações dissertativas ficaram categorizadas em inadequadas por $58 \%$ dos participantes da E1, $11 \%$ da E2 e $29 \%$ da E3, fragmentadas pela E2 com $33 \%$ e E3 com $14 \%$ e adequadas pelas E1 e E2, com $33 \%$ cada (Figura $8 b$ )

Figura 8 - A) Percentual por escola das respostas da pergunta: Você tem conhecimento sobre espécie nativa e exótica. B) Categorização das respostas descritivas

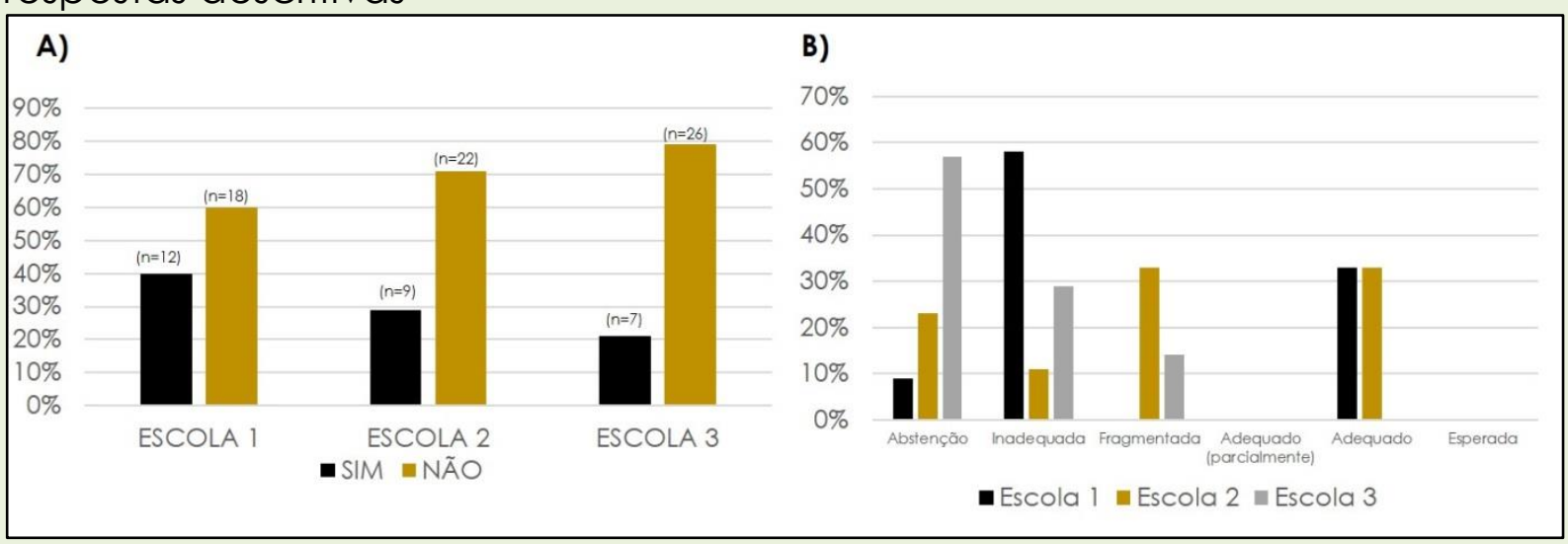

Fonte: Dados da Pesquisa.

As respostas categorizadas como inadequadas variaram entre aqueles alunos que indicaram saber o que seria e, depois, no momento da descrição, informaram que não lembravam, ou quando relacionaram espécies da região de fácil localização como nativas e espécies de difícil localização como sendo as exóticas ou, ainda, quando fizeram relação com os índios, como percebe-se nas respostas dos alunos:

A6 - Não lembro; 
A31 - Espécie nativa é quando se encontra facilmente na região e espécie exótica é algo difícil de ser encontrado;

A84 - Sobre os índios e diferentes no nosso dia a dia.

No questionamento sobre biopirataria, predominou, em $80 \%$ da El, $87 \%$ da E2 e 79\% da E3, a resposta de desconhecimento sobre o tema (Figura 9a). Em uma pequena parcela que indicou saber sobre o assunto, $100 \%$ de E2 e $66 \%$ de $\mathrm{El}$ foram de respostas inadequadas. Adequadas parcialmente foram as respostas de E3, com $57 \%$, fragmentada foram $14 \%$ das respostas de E3 e adequadas foram $34 \%$ das respostas de E1 (Figura 9b).

Figura 9. A) Percentual por escola das respostas da pergunta: Você tem conhecimento sobre biopirataria. B) Categorização das respostas descritivas

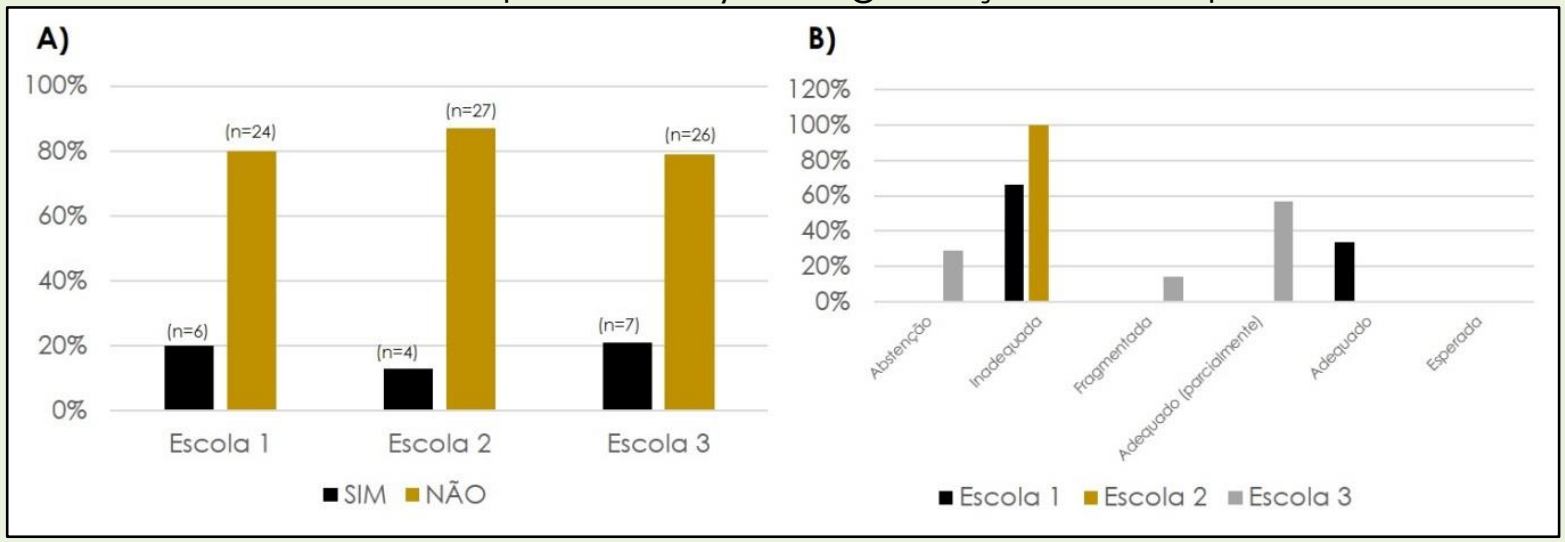

Fonte: Dados da Pesquisa.

As respostas inadequadas relacionaram apenas a pirataria ou cópias de elementos da natureza, sem relacionar, como observado nas respostas dos alunos:

A15 - É a pirataria de biologia;

A18 - Nem lembro, mas eu acho que é algo que fazem para copiar plantas sei lá;

A46 -É um bioma que o ser humano inventou (plantou). 
Já as respostas categorizadas como parcialmente adequadas relacionam a pirataria com animais e plantas, porém de espécies em extinção:

A89 - Pirataria de animais de plantas em extinção.

A94 - A pirataria de árvores e plantas em extinção.

$E$ as respostas categorizadas como adequadas relacionaram a biopirataria com contrabando e tráfico de espécies, bem como sendo algo ilegal, como pode ser visto nas respostas dos alunos:

A6 - Acho que é quando nossos animais são contrabandeados, ou quando madeira explorada é passada para outro país ou estado ilegalmente;

A26 - É o tráfico de espécies sejam raras e nativas e exóticas.

\section{ANÁLISE E DISCUSSÃO}

Quanto ao perfil dos grupos, foi possível verificar que a representação das escolas foi muito similar, em relação ao número de alunos, assim como o número de participantes femininos e masculinos foram muito parecidos no contexto geral, já individualmente, o público feminino foi mais expressivo na El.

A presente investigação indica que as percepções dos alunos foram inadequadas, sugerindo que as temáticas questionadas não foram desenvolvidas corretamente no ensino fundamental. Para Morin (2000), isso é reflexo do sistema educacional brasileiro, que desde os anos iniciais fragmenta o conhecimento isolando-o em disciplinas, sem que ocorra interação entre as áreas do conhecimento e, muito menos, com as problemáticas ambientais presente no cotidiano das comunidades escolares.

Os PCN's norteiam para um ensino diferenciado ao frisarem a necessidade de desenvolvimento das temáticas ambientais, indicando-as nos conteúdos do ensino fundamental, além de orientarem aos professores 
para que os temas sejam sempre relacionados com a realidade dos alunos (BRASIL, 1998b).

A Base Nacional Comum Curricular (BRASIL, 2018), para o ensino fundamental também frisa a necessidade dos principais ecossistemas brasileiros para o desenvolvimento de habilidade pelos estudantes.

Frente a isso, é possivel observar que o primeiro bloco de questões está relacionado aos temas que compõem os conteúdos de ciências do ensino fundamental e que devem ser desenvolvidos e aprimorados em todo ensino básico, para uma melhor compreensão dos ecossistemas brasileiros.

As análises contribuíram para revelar que os alunos das três unidades escolares desconhecem o tema bioma, principalmente quando o descrevem de maneira confusa. O mesmo ocorreu especificamente com a descrição do bioma Pampa, embora um tema próximo da realidade dos alunos, a maioria indicou não conhecer.

Esses dados foram muito semelhantes com os encontrados por Correa (2008), ao identificar que estudantes do ensino básico, que moravam no Pampa, desconheciam o bioma. Ainda, Paris et al., (2016) inferiram que estudantes do ensino médio do norte do estado do Rio Grande do Sul tinham uma percepção genérica e superficial sobre o Pampa, contudo, a qualidade das informações dos estudantes pesquisados pelos autores são consideráveis quando comparadas com o estudo de Correa (2008).

Dessa forma, a presente pesquisa pressupõe que os estudantes estariam aprendendo mais sobre outros biomas ao invés de obter conhecimento sobre os ecossistemas locais, dados, esses, corroborados por Pessano (2012), ao identificar que alunos da educação básica desconheciam o rio Uruguai, o rio mais importante da região e que circunda a cidade de Uruguaiana-RS, onde o estudo foi realizado.

Essa percepção inadequada e fragmentada, diagnosticada sobre o bioma Pampa, enfatiza a descontextualização do ensino para com as questões pertinentes ao entorno dos alunos, pois, segundo Proença et al. (2014), é preciso conhecer para preservar. O autor, ainda, aponta que o currículo do ensino fundamental precisa contemplar questões da 
biodiversidade nativa, proporcionando conhecimento sobre as espécies regionais, o que acarreta na valorização de vivências com o ambiente (PROENÇA et al., 2014).

Estes dados quando relacionados aos de Castro et al. (2019), que ao analisarem livros didáticos de ciências sobre a perspectivas dos biomas brasileiros evidenciaram que o Pampa foi o bioma menos abordado nos recursos pedagógicos mais utilizados atualmente na educação Brasileira.

Tudo isso quando relacionado aos dados apontados na presente pesquisa é possível perceber que há um distanciamento da escola com as questões ambientais locais. Evidenciando a necessidade de o professor estar preparado para associar o conteúdo específico de sua área com as questões locais e atuais, garantindo que a educação ambiental permeie o currículo escolar (MEDEIROS, 2016).

Foi possível observar que os conteúdos ambientais não foram explorados nas três escolas quando os alunos, por exemplo, percebem o meio ambiente de maneira conservadora, onde descrevem apenas cuidados, ou quando percebem o ambiente de maneira estética ao relacionarem-no com elementos isolados ou, ainda, quando o descrevem, não se incluem como parte do mesmo. Frente a isso, é possível destacar que os alunos não foram capacitados para observar o próprio ambiente em que vivem.

Souza e Silva (2016), quando analisaram a percepção ambiental no contexto escolar da Caatinga, perceberam que os alunos associavam o bioma aos fatores abióticos, com uma tendência de perceber menos a biodiversidade. Já Araújo e Sovierzoski (2016), quando estudaram a percepção ambiental de estudantes do ensino básico, identificaram que os alunos tinham uma visão naturalista ao descreverem o meio ambiente como a localidade dos seres vivos.

Corroborando com isso, os estudos de Santos et al., (2013) identificaram que professores e alunos possuíam uma perspectiva unicamente ecológica e dissociavam a ideia de fazerem parte do ambiente, sendo considerado um problema pelos autores, já que os 
indivíduos, ao não se reconhecerem no ambiente, não se reconhecerão como agentes impactantes do mesmo. E, nessa linha de pensamento, Araújo e Sovierzoski (2016) ressaltaram a necessidade do desenvolvimento de ações que amplicassem as visões dos alunos.

Neste ponto da pesquisa, é possível perceber que o tema meio ambiente deveria estar sempre presente no caminho educacional dos estudantes, para desenvolverem suas relações com o ambiente. Desse modo, também associarem aos outros temas, como os biomas e ecossistemas brasileiros, parte dos conteúdos educacionais, importantes de serem conhecidos e interpretados, como apontam os PCN's, ao ponto de os alunos e professores discutirem sobre assuntos de interesse local ou atualidades, para que, dessa maneira, por meio de discussão, ocorra o desenvolvimento dos aprendizes com a amplitude de suas visões.

O presente estudo revela que essa associação de conteúdos e temas locais não esteve próximo dos alunos, o segundo bloco de questões retrata isso de forma muito clara quando grande parte dos alunos não reconheceram os temas monocultura, espécies nativas e exóticas e biopirataria, cuja as respostas foram inadequadas.

Quanto à monocultura, os resultados indicaram que os alunos desconheciam a mesma, que é um dos maiores setores responsáveis pela economia da região, além de ser, de acordo com Pillar (2006), uma das atividades mais impactantes que ocorrem no Pampa. Esse desconhecimento também foi evidenciado na temática sobre as espécies nativas e exóticas, que, segundo Ziller (2016), é um dos maiores problemas ambientais no estado do Rio Grande do Sul.

Consequentemente, não é possível afirmar que os temas não foram abordados no ambiente escolar, entretanto, é possível inferir que os temas não apresentaram sentido para os alunos devido ao grande desconhecimento apresentado, o que, para Santos et al., (2013), é um problema, porque o indivíduo não se reconhece como parte do ambiente em que vive e, com isso, não reflete sobre suas próprias atitudes. 
$\mathrm{Na}$ visão de Proença (2014), o ambiente escolar é ideal para proporcionar situações de aprendizagem que possam garantir que o aluno se familiarize com o ambiente natural. O autor, ainda, indica a necessidade de incentivar a preservação, incluir atividades pedagógicas que busquem trabalhar as espécies da região a qual os alunos estão inseridos, para que, de forma contextualizada, o conhecimento tenha um significado (PROENÇA, 2014).

Pessano et al., (2015) apostam na contextualização como forma de aproximação dos alunos com os conteúdos e de melhoria dos resultados escolares, porém, para que isso ocorra, o empenho da escola e de seus professores é necessário.

Machado e Abílio (2016), ao estudarem a percepção ambiental no ensino básico da Caatinga, identificaram que os educadores apresentavam uma visão simplista e naturalista em abordar temas ambientais e estes preferiam manter $o$ formato tradicional e evitavam abordagens que exigissem embasamento teórico.

Santos et al., (2016), ao estudarem a percepção ambiental de professores no mesmo bioma, identificaram a dificuldades dos mesmos em contextualizar o ensino com o ambiente regionalizado. Já Machado e Abílio (2016) apontaram que os educadores conheciam os problemas da Caatinga e que o problema de desenvolver os temas estava relacionado apenas com a efetivação das ações, devido às excessivas cargas de trabalho, além da falta de materiais didáticos e paradidáticos contextualizados com o bioma.

Desta forma, para Santos et al., (2016), os temas ambientais regionais acabam sendo abordados de forma ampla, sem relação nenhuma com a realidade, fatores que contribuem para a limitação do conhecimento ambiental local. De acordo com Santos e Trevisan (2009), a falta de conhecimento básico sobre a biodiversidade local aumenta o descaso com o Pampa e atribui, ainda mais, a chancela de bioma negligenciado. 


\section{CONSIDERAÇÕES FINAIS}

Perceber que a sociedade está distante de assuntos ambientais próximos ao seu cotidiano é muito mais que um descaso ambiental, é o início de um problema ambiental imensurável. Os resultados permitem inferir que os estudantes do ensino fundamental participantes da pesquisa possuem percepções inadequadas e Fragmentadas do bioma Pampa, sendo essa etapa do ensino a base para o desenvolvimento das capacidades que serão trabalhadas no ensino médio, sem isso as etapas de ensino deixam lacunas que serão repercutidas nos futuros cidadãos e na sociedade.

Em uma análise na Base Nacional Comum Curricular (Brasil, 2018) para o segundo ciclo do ensino fundamental é possível observar que os principais ecossistemas brasileiros devem ser caracterizados pelos estudantes, para que estes possam relacioná-los com a biodiversidade para despertar a consientização em prol da preservação.

Nessa diretriz, a pesquisa sugere que estudos de investigação devem ser realizados em todas as etapas do ensino básico, inclusive com os educadores, para que seja possível identificar as prováveis falhas no desenvolvimento dos temas ambientais. As práticas e as estratégias de ensino devem ser revistas, com base no tema bioma Pampa, como intervenções para os estudantes, mas também como ações fundamentadas em técnicas problematizadoras e contextualizadoras diretamente planejadas para os educadores, com o propósito de efetivamente contribuir com a formação continuada dos mesmos, visto que são eles os agentes da mudança e da formação dos estudantes no processo de ensino e aprendizagem, onde, o conhecimento sobre os assuntos ambientais se tornam imprescindíveis para a formação de cidadãos, críticos e reflexivos.

\section{AGRADECIMENTOS}

À Coordenação de Aperfeiçoamento de Pessoal de Nível Superior (CAPES) pelo apoio financeiro concedido à bolsa de estudos para cursar o 
Mestrado no Programa de Pós-Graduação em Educação em Ciências: Química da Vida e Saúde da Universidade Federal de Santa Maria UFSM/RS e o Doutorado na Universidade Federal do Pampa.

\section{REFERÊNCIAS}

ARAÚJO, B. F. e SOVIERZOSKI, H. H. Percepção dos alunos do ensino médio sobre os biomas de Mata Atlântica e Caatinga. Revista Práxis, v. 8, n. 16 , p.81-94, 2016.

BENCKE, G. Monoculturas podem decretar o fim dos pampas. [Entrevista concedida a. Revista do Instituto Humanistas Unisinos, v.1, n. 190.p.10-13, 2006.

BENCKE, G. Pampa: uma fronteira em extinção. [Entrevista concedida a Revista do Instituto Humanistas Unisinos. v.1, n. 247.p.29-32, 2007.

BIGLIARDI, R. V. e CRUZ, R. G. Currículo escolar, pensamento crítico e educação ambiental. Rev. Eletrônica Mestr. Educ. Ambient. v. 21, p. 332340, 2008.

BOLDRINI, I.L., FERREIRA, P.M.A., ANDRADE, B.O., SCHNEIDER, A.A., SETÚBAL, R.B., TREVISAN, R. E FREITAS, E.M. Bioma Pampa: diversidade florística e fisionômica. Porto Alegre. ed. Pallotti, 2010.

BORTOLUZZI, L. R. e SOUZA, M. V. O dia do Bioma Pampa. Biodiversidade Pampeana, v.5, n. 2, p.1-1. 2007.

BORTOLUZZI, L. R., QUEROL, M. V. M. e QUEROL, E. Notas sobre a ocorrência de Tityus serrulatus (Lutz \& Mello, 1922) (Scorpiones, Buthidae) no oeste do Rio Grande do Sul, Brasil. Biota Neotropica, São Paulo, v. 2, n. 3, p. 357-359, 2007.

BRACK, P. O pampa gaúcho é alvo de biopirataria, denuncia ambientalista. [Entrevista concedida a Revista do Instituto Humanistas Unisinos. v. 1, n. 247.p.13-17, 2007.

BRACK, P., KINUPP, V.F. e SOBRAL, M.E.G. Levantamento preliminar de Espécies Frutíferas de Árvores e Arbustos Nativos com uso atual ou potencial do Rio Grande do Sul. Revista Brasileira de Agroecologia, v.2, n.1, p.1-4. 2007.

BRASIL. Mapa de Biomas do Brasil, primeira aproximação. Instituto Brasileiro de Geografia e Estatística - IBGE. Rio de Janeiro: IBGE. 2004

BRASIL. Base Nacional Comum Curricular: Versão Final. Ministério da Educação. Brasília, DF, 600p. 2018.

BRASIL. Monitoramento do Desmatamento nos Biomas Brasileiros por Satélite. Ministério do Meio Ambiente. 1. ed. Brasília, DF, 29 p. 2011. 
BRASIL. Parâmetros curriculares nacionais: tema transversal ética / Secretaria de Educação Fundamental. - Brasília: MEC/SEF, 1998a.

BRASIL. Parâmetros curriculares nacionais: Ciências Naturais / Secretaria de Educação Fundamental. Brasília: MEC / SEF, 1998b.

CAMARGO, R. F. O ensino de solos na escola pública: o caso na Escola Estadual Jardim Monza. [S.I.]. Trabalho de Conclusão de Curso (Graduação em Agronomia) -Departamento de Solos e Engenharia Agrícola, Universidade Federal do Paraná, UFPR, Curitiba, 2003.

CASTRO, L. R. B; CARVALHO, A. V; SOARES, J. R; PESSANO, E. F. C. Os Biomas Brasileiros nos livros didáticos de Ciências: Um olhar ao Pampa Gaúcho.

Revista Electrónica De Investigación En Educación En Ciencias, v. 14, n. 1, p. 38-49, 2019.

CHOMENKO, L. O pampa no atual modelo de desenvolvimento econômico. [Entrevista concedida a Revista do Instituto Humanistas Unisinos. v. 1, n. 190.p.22-30, 2006.

CHOMENKO, L. Recursos Hídricos E Áreas Úmidas: Ambientes A Serem Preservados. In: ZAKRZEVSKI, S.B. (Organ.) Conservação e uso sustentável da água: múltiplos olhares. Erechim, RS: EdiFapes, 2007.

CORREA, M. L. Origem do Descaso com o Bioma Pampa. Monografia. (Especialização em Educação Ambiental). Centro Universitário La Salle. Canoas/RS. 134p. 2008.

DÁVILA, E. S., FOLMER, V.; PUNTEL, R. L. Concepções de professoras de ciências sobre o ensino de ciências. Exitus, V. 7, n. 2, p. 237-261, 2017.

DEBLE, A. S. O.; DEBLE, L. P.; LEÃO, A. L. S. Bioma pampa: ambiente $\mathbf{x}$ sociedade- Bagé: Ediurcamp,2012.

KÖNIG, F., GONÇALVES, C.E.P., AGUIAR, A.R.; SILVA, A.C.F. Bioma Pampa: Interações entre micro-organismos e espécies vegetais nativas. Lisboa.

Revista de Ciências Agrárias, V.37. n.1 p.3-9, 2014.

LANNA, A. E. O bioma pampa em risco? A plantação de pínus e eucaliptos. [Entrevista concedida a Revista do Instituto Humanistas Unisinos. v. 1, n. 247.p.18-22, 2007.

MACHADO, M. G.; ABÍLIO, F. J. P. Educação ambiental no bioma caatinga: percepção ambiental dos professores da educação de jovens e adultos em uma escola pública do cariri paraibano. In: I Congresso Internacional da Diversidade do Semiárido. 2016. 
MADEIRA, M. Zoneamento Ambiental da Silvicultura. Um documento morto? [Entrevista concedida a Revista do Instituto Humanistas Unisinos. v. 1, n. 247.p.08-12, 2007.

MAZURANA, J., DIAS, J. E. e LAUREANO, L. C. Povos e Comunidades

Tradicionais do Pampa. Porto Alegre: Fundação Luterana de Diaconia, 2016. 224p.

MEDEIROS, I. A. F. de. Bioma Caatinga por uma educação ambiental contextualizada para a RPPN Fazenda Santa Clara, São João do Cariri, Paraíba. Monografia (Licenciatura em Ciências Biológicas) Universidade Federal da Paraíba, João Pessoa/PB.100p.2016.

MORIN, E. A cabeça bem-feita repensar a reforma reformar o pensamento. 8Edição. Rio de Janeiro: Bertrand Brasil, 2000.

OVERBACK, G. E., MÜLLER, S. C., FIDELIS, A., PFADENHAUER, J., PILLAR, V. D.; BLANCO, C. C., BOLDRINI, I. I., BOTH, R. e FORNECK, E. D. Os Campos Sulinos: um bioma negligenciado. In: PILLAR, V. P., MÜLLER, S. C., CASTILHOS, Z. M. S. e JACQUES, A. V. A. (EDS.). Campos Sulinos, conservação e uso sustentável da biodiversidade. 1. ed. Brasília: MMA, 2009.

PALMA, I. R. Análise da percepção ambiental como instrumento ao planejamento da Educação Ambiental. Dissertação (Mestrado em Engenharia) - Escola de Engenharia, Universidade Federal do Rio Grande do Sul, 2005.

PARIS, A. M. V., WARNAVA, F. P., DECIAN, V. S. e ZAKRZEVSKI, S.B. O que os jovens gaúchos que residem na Mata Atlântica pensam sobre o Pampa? Perspectiva. V. 40, n. 152, p. 111-123. 2016

PESSANO, E. F. C. O uso do rio Uruguai como tema gerador para a educação ambiental no ensino fundamental. Dissertação de Mestrado do Programa de Pós-Graduação em Educação em Ciências, Química da Vida e Saúde. UFSM, Santa Maria. 2012.

PESSANO, E.F.C., PESSANO, C.L.A., FOLMER, V. e PUNTEL, R.L. O Rio Uruguai Como Tema Para a Educação Ambiental no Ensino Fundamental. Revista Contexto \& Educação, ljuí, V.30, n.96, p.29-63, 2015.

PILLAR, V. De P. Reforma agrária é compatível com conservação dos campos. [Entrevista concedida a Revista do Instituto Humanistas Unisinos. v.1, n. 190.p.14-17, 2006.

POLLI, A. e SIGNORINI, T. A inserção da educação ambiental na prática pedagógica. Ambiente \& Educação, Anápolis-GO, v. 17, n.2, p. 93-101, 2012.

PROENÇA, M. S., OSLAJ, E. U.; DAL-FARRA, R. A. As percepções de estudantes do ensino fundamental em relação as espécies exóticas e o efeito antrópico 
sobre o ambiente: Uma análise com base nos pressupostos da CTSA Ciência, Tecnologia, Sociedade, Ambiente. Pesquisa em Educação Ambiental, v. 9, n. 2, p. 51-66, 2014.

SANTOS, J. O. dos., SANTOS, R. M. S., SANTOS SEGUNDO, J. O.; SANTOS V. C. Análise da percepção ambiental acerca do bioma Caatinga por parte dos docentes de uma escola pública do município de Patos, Paraíba. REGNE, v. 2, n. Especial. p.760-769, 2016.

SANTOS, K. G. F. Contribuição dos pecuaristas à sustentabilidade do Bioma Pampa no município de Quaraí, RS. Monografia apresentada ao Curso de Especialização da Universidade Federal de Santa Maria, 2015.

SANTOS, P.J.A., SILVA, M. M. P., COUTO.M.G.; BORGES, V. G. Relação entre a percepção ambiental de docentes e discentes do ensino fundamental II de uma escola pública do semiárido paraibano com as características do bioma caatinga. Rev. Eletrônica Mestr. Educ. Ambient. V. 30, n. 1, p. 38 - 53. 2013.

SANTOS, T.; TREVISAN, R. Eucaliptos versus Bioma Pampa: compreendendo as diferenças entre lavouras de arbóreas e o campo nativo. In: Teixeira-Filho, A. (Org.). Lavouras de Destruição: a (im)posição do consenso. Pelotas, RS, Simapiris, 2009, p. 299-332.

SOUZA, L.S. e SILVA, E. Percepção ambiental do bioma caatinga no contexto escolar. Revista Iberoamericana de Educación.v. 73, n.1 p. 67-86. 2016.

SOUZA, M. C. C. Educação Ambiental e as trilhas: Contexto para sensibilização ambiental. Revbea, São Paulo, v.9, n.2, p. 239-253, 2014.

SPIRONELLO, R.L., TAVARES, F. S. E SILVA, E.P. Educação ambiental: da teoria à prática, em busca da sensibilização e conscientização ambiental. Revista Geonorte, v.3, n.4, p.140-152, 2012.

SUERTEGARAY, D. M. A. e SILVA, L. A. P. Tchê Pampa: histórias da natureza gaúcha. In: Campo Sulinos - conservação e uso sustentável da biodiversidade. Brasília, 2009, p. 42-59.

ZILLER, S. Estratégias e políticas públicas para o controle das espécies exóticas invasoras. In: Instituto Hórus (Org.) Publicações do Projeto RS Biodiversidade. Porto Alegre, Fepam, 2016, p.01-52.

Recebido em: 05 de janeiro de 2018 Aprovado em: 17 de outubro de 2018 